\title{
Adrenal Androgen Predictive Effects on Clinical and Metabolic Abnormalities of Polycystic Ovary Syndrome
}

\section{Efeitos preditivos dos androgênios adrenais nas anormalidades clínicas e metabólicas da síndrome dos ovários policísticos}

Sebastião Freitas de Medeiros ${ }^{1,2}$ Bruna Barcelo Barbosa ${ }^{2}$ Matheus Antônio Souto de Medeiros ${ }^{2}$ M Ana Karine Lin Winck Yamamoto ${ }^{30}$ Márcia Marly Winck Yamamoto ${ }^{2}{ }^{\circ}$

1 Department of Gynecology and Obstetrics, Medical School, Universidade Federal do Mato Grosso, Cuiabá, MT, Brazil

2 Instituto Tropical de Medicina Reprodutiva, Cuiabá, MT, Brazil

3 Universidade de Cuiabá, Cuiabá, MT, Brazil
Address for correspondence Sebastião Freitas de Medeiros, MD, PhD, Rua Quarenta e Nove, 2367, 78060-900, Boa Esperança, Cuiabá, MT, Brazil (e-mail: de.medeiros@terra.com.br).

Rev Bras Ginecol Obstet 2022;44(2):142-153.

\begin{abstract}
\section{Keywords}

- polycystic ovary syndrome

- hyperandrogenism

- obesity

- hyperinsulinemia

- metabolism

Objective To examine the possible effects of adrenal prohormones in the prediction of clinical and metabolic abnormalities in women with polycystic ovary syndrome (PCOS). Methods The present study enrolled 299 normal cycling non-PCOS, 156 normoandrogenemic, and 474 hyperandrogenemic women with PCOS. Baseline characteristics were compared using a chi-squared test or analysis of variance (ANOVA) as appropriate. The roles of adrenal prohormones and their ratios with total testosterone in predicting co-occurring morbidities in women PCOS were evaluated using univariate and multivariate logistic regression analyses.

Results Adrenal hyperandrogenism per dehydroepiandrosterone sulfate (DHEAS) levels were found in $32 \%$ of women with PCOS. In non-PCOS women, dehydroepiandrosterone (DHEA) and its sulfate had no predictive role concerning clinical, anthropometric, and metabolic parameters. In PCOS women, mainly in the hyperandrogenemic group, DHEA showed to be a significant predictor against most anthropometric-metabolic index abnormalities (odds ratio $[O R]=0.36-0.97 ; p<0.05$ ), and an increase in triglycerides (TG) levels $(\mathrm{OR}=0.76 ; p=0.006)$. Dehydroepiandrosterone sulfate presented a few predictive effects regarding PCOS-associated disorders. In controls, DHEAS predicted against the increase in estimated average glucose $(O R=0.38 ; p=0.036)$. In the normoandrogenic group, it predicted against elevation in the waist/hip ratio (WHR) (OR=0.59; $p=0.042)$, and in hyperandrogenemic PCOS women, it predicted against abnormality in the conicity index $(\mathrm{Cl})(\mathrm{OR}=0.31 ; p=0.028)$.
\end{abstract}

received

January 22, 2021

accepted

September 15, 2021
DOI https://doi.org/

10.1055/s-0041-1741030. ISSN 0100-7203. (c) 2022. Federação Brasileira de Ginecologia e Obstetrícia. All rights reserved.

This is an open access article published by Thieme under the terms of the Creative Commons Attribution License, permitting unrestricted use, distribution, and reproduction so long as the original work is properly cited. (https://creativecommons.org/licenses/by/4.0/)

Thieme Revinter Publicações Ltda., Rua do Matoso 170, Rio de Janeiro, RJ, CEP 20270-135, Brazil 


\section{Resumo}

Palavras-chave

- síndrome dos ovários policísticos

- hiperandrogenismo

- obesidade

- hiperinsulinemia

- metabolismo
Conclusion Dehydroepiandrosterone was shown to be a better predictor of abnormal anthropometric and biochemical parameters in women with PCOS than DHEAS. Thus, regarding adrenal prohormones, DHEA measurement, instead of DHEAS, should be preferred in PCOS management. The effects of androgen prohormones on the prediction of PCOS abnormalities are weak.

Objetivo Examinar os possíveis efeitos dos pró-hormônios adrenais na predição de alterações clínicas e metabólicas em mulheres com síndrome dos ovários policísticos (SOP). Métodos O presente estudo envolveu 299 mulheres com ciclos menstruais regulares e 630 mulheres com SOP, sendo 156 normoandrogenêmicas e 474 hiperandrogenêmicas. As variáveis incluídas como objeto do estudo foram comparadas entre os grupos usando o teste de qui-quadrado ou análise de variância (ANOVA, na sigla em inglês). Os impactos dos pró-hormônios adrenais e suas razões com a testosterona total na predição de comorbidades em mulheres com SOP foram determinados por regressão logística univariada e multivariada.

Resultados Hiperandrogenismo adrenal foi encontrado em 32\% das mulheres com SOP. Nos controles, a dehidroepiandrosterona e seu sulfato (DHEAS) não mostraram significância na predição das alterações clínicas, antropométricas e metabólicas. Em mulheres com SOP, principalmente no grupo de mulheres com hiperandrogenemia, a dehidroepiandrosterona (DHEA) mostrou ser um preditor significante da maioria das anormalidades nos índices antropométrico-metabólicos (odds ratio $[O R]=0,36-0,97$; $p<0,05)$ e aumento nos níveis de triglicerídeos (TG) $(\mathrm{OR}=0,76 ; p=0,006)$. A DHEAS apresentou ter pouco valor na predição dos distúrbios associados à SOP; nas mulheres com androgênios elevados, restringiu-se à predição da elevação do índice de conicidade (IC) $(\mathrm{OR}=0,31 ; p=0,028)$.

Conclusão A DHEA mostrou ser um melhor preditor na identificação das alterações dos parâmetros antropométricos e bioquímicos em mulheres com SOP do que o seu sulfato. Assim, em relação aos pró-hormônios adrenais, a dosagem de DHEA, em vez de DHEAS, parece ser mais útil no manejo da SOP. O papel dos pró-hormônios adrenais na predição de anormalidades antropométricas e metabólicas da SOP é limitado.

\section{Introduction}

Polycystic ovary syndrome (PCOS) is found in up to $20 \%$ of women of reproductive age. ${ }^{1}$ Since 1990 , PCOS has been defined by the presence of oligoanovulation, clinical or biochemical hyperandrogenism, and/or polycystic ovary morphology (PCOM) ${ }^{2-4}$ The main characteristic of PCOS appears to be hyperandrogenism because PCOS women with high levels of androgens have increased risk for the development of central obesity, dysfunctional adipocyte, impaired fasting glucose (IFG), glucose intolerance (GI), insulin resistance (IR), dyslipidemia, metabolic syndrome (MS), low-grade chronic inflammation, nonalcoholic fatty liver disease (NAFLD), nonalcoholic steatohepatitis (NASH), and, in the end, cardiovascular disease (CVD). ${ }^{5-10}$ All these harmful co-occurring conditions, to a certain extent, are associated with hyperandrogenemia. ${ }^{11-14}$

Strong androgens, such as testosterone ( $\mathrm{T}$ ), direct macrophages toward adipocytes, induce adipocyte hypertrophy, promote visceral obesity, decrease adipocyte sensitivity to insulin, and decrease adipocyte glucose uptake. ${ }^{15-19}$ Conversely, it appears that the adrenal prohormones dehydroepiandrosterone (DHEA) and dehydroepiandrosterone sulfate (DHEAS) have a beneficial effect by inhibiting the proliferation and differentiation of subcutaneous adipocyte and adipogenesis in omental adipocyte and enhancing adipocyte glucose uptake. ${ }^{20-22}$ Furthermore, DHEA seems to exert antiglucocorticoid action on preadipocyte proliferation and differentiation, and DHEAS stimulates lipolysis. 23,24

Different effects of adrenal prohormones on the development of harmful subphenotypes in PCOS, when compared with the effects of testosterone and free testosterone index, have been reported. ${ }^{25,26}$ The present study expands and amplifies the initial findings by examining separately women with PCOS who were classified as normoandrogenemic (NA-PCOS) and hyperandrogenemic (HA-PCOS) and comparing them with non-PCOS normal-weight controls. Therefore, the present study proposed to examine the possible beneficial effects of adrenal prohormones in preventing clinical abnormalities in women with PCOS. The secondary objective 
was to verify the influence of adrenal products on carbohydrate and lipid metabolism biomarkers.

\section{Methods}

\section{Subjects, Design, Eligibility Criterion}

The present cross-sectional study enrolled 630 women with PCOS, aged $27.6 \pm 5.4$ years old, and 299 normal cycling nonobese controls, aged $29.9 \pm 4.8$ years old $(p<0.001)$, in whom DHEA and DHEAS were measured; all of them were attended at the outpatient clinic of the Instituto Tropical de Medicina Reprodutiva and at the Hospital Universitário Julio Muller, Cuiabá, state of Mato Grosso, Brazil, between 2003 and 2019. Women with PCOS were further divided into 156 (24.8\%) NA-PCOS and 474 (75.2\%) HA-PCOS. These subjects were enrolled from a previously described large sample of women with PCOS. ${ }^{27}$ Every patient gave full-informed written consent by signing a form approved by the local Ethics in Research Committee (decision No.093/FCM/03). Late-onset adrenal enzyme deficiencies were excluded as follows: 21hydroxylase (17-hydroxyprogesterone [17-OHP4] levels $\leq$

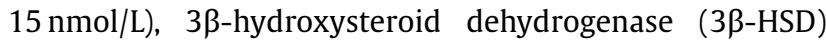
(17-hydroxypregnenolone [17-OHPE] $\leq 13.5 \mathrm{nmol} / \mathrm{L})$, and 11-hydroxylase (compound $\mathrm{S} \leq 23 \mathrm{nmol} / \mathrm{L}$ ). Hypothyroidism was excluded by thyroid-stimulating hormone (TSH) level $\leq$ $4.2 \mu \mathrm{UI} / \mathrm{mL}$, free thyroxin $(\mathrm{FT} 4) \leq 9.0 \mathrm{pmol} / \mathrm{L}$, and hyperprolactinemia by prolactin $(\mathrm{PRL}) \leq 1.1 \mathrm{pmol} / \mathrm{L} .{ }^{9,28}$ Women with PCOS who had used sex steroids, insulin-sensitizing, or dipeptidyl peptidase- 4 inhibitors over the previous 6 months or those who did not fulfill the Rotterdam criteria were excluded.

\section{Definitions}

Polycystic ovary syndrome was diagnosed using the Rotterdam criteria, after exclusion of other hyperandrogenic conditions. ${ }^{28}$ The normal menstrual cycle was defined by a menstrual interval of between 24 and 35 days; amenorrhea was defined by the absence of a menstrual period for $\geq$ 90 days. ${ }^{29}$ Frequent menses were defined as an interval $<24$ days or as $>4$ menstrual episodes in 90 days, and infrequent menses were defined as a menstrual cycle $\geq 35$ days or as $\leq 8$ menstrual periods in the previous year. ${ }^{30}$

Because of inconsistent results due to ethnicity and interrater evaluation, clinical hyperandrogenism was registered as a dichotomous variable according to the complaints of the patient and the presence or lack of hirsutism in the upper lip, chin, chest, upper or lower back, upper or lower abdomen, upper arms, and thighs in the medical examination. ${ }^{31-33}$ Biochemical hyperandrogenism was defined by at least 1 of the following criteria: total $\mathrm{T} \geq 1.75 \mathrm{nmol} / \mathrm{L}$, free testosterone $(\mathrm{FT}) \geq 0.032 \mathrm{pmol} / \mathrm{L}$, DHEAS $\geq 6.6 \mu \mathrm{mol} / \mathrm{L}$, androstenedione (A4) $\geq 9.4 \mathrm{nmol} / \mathrm{L}$, DHEA $\geq 34 \mathrm{nmol} / \mathrm{L}$, and free androgen index $(\mathrm{FAI}) \geq 5.2 \%$. All these cutoff values were $\geq$ $90^{\text {th }}$ percentile of 425 normal cycling, normal weight, nonPCOS women. ${ }^{33}$

Impaired fasting glucose (IFG) was defined by fasting plasma glucose concentration $>100 \mathrm{mg} / \mathrm{dL} \quad(5.5 \mathrm{mmol} / \mathrm{L})$ or $<126 \mathrm{mg} / \mathrm{dL}(7.0 \mathrm{mmol} / \mathrm{L})$. Glucose intolerance (GI) was defined by a glucose concentration $\geq 7.8 \mathrm{nmol} / \mathrm{L}$ at 120 minutes after the ingestion of dextrose. Insulin resistance (IR) was defined by fasting insulin levels $>90 \mathrm{pmol} / \mathrm{L}$ and/or a HOMA-IR value $\geq 2.6$. $^{33}$ Type 2 diabetes mellitus (T2DM) was defined as fasting plasma glucose $\geq 126 \mathrm{mg} / \mathrm{dL}$ $(7.0 \mathrm{mmol} / \mathrm{L})$ or glucose $\geq 200 \mathrm{mg} / \mathrm{dL}(11.1 \mathrm{mmol} / \mathrm{L})$ at 120 minutes after the ingestion of dextrose. ${ }^{34}$

\section{Ultrasound Evaluation}

Ovarian morphology was examined by ultrasonography using a vaginal transducer with a frequency of between 5 and $8 \mathrm{MHz}$ (Toshiba Xario SSA-660A, Toshiba Medical do Brazil LTDA, Taboão da Serra, SP, Brazil or Voluson E8, GE Health Care, Bedford, United Kingdom). Antral follicle count $\geq 20$ follicles in at least 1 ovary and ovarian volume $\geq 10 \mathrm{~cm} 3$ were the reference for assuming PCOM. The ovarian volume was calculated by the ellipsoid formula: $\pi / 6 \times \mathrm{D} 1 \times \mathrm{D} 2 \times \mathrm{D} 3$, where D1, D2, and D3 were taken as the maximum diameters. $^{29}$

\section{Clinical and Anthropometric Parameters}

All data were registered in a template used in both institutions; however, in some participants, a few observations completely at random were not recorded. Systolic blood pressure (SBP) and diastolic blood pressure (DBP) were measured with the study participants in a sitting position after at least 5 minutes of resting. Height was measured using a harpenden stadiometer (Holtain Ltd., Crymych, Dyfed, UK). Body weight was acquired using an electronic scale, and the waist circumference (WC) was measured as the narrowest measuring midway point between the lower rib margin and the iliac crest, and the hip was measured at the widest circumference at the greater trochanters. Body mass index (BMI) was calculated from the ratio between weight and height squared, despite the limitations of indirect measurement. Lean body mass (LBM) was calculated using the James $^{35}$ equation. Fat mass (FM) was calculated as body weight minus LBM. Body shape index (BSI) was calculated according to the formula: $\mathrm{WC}(\mathrm{cm}) /\left[\mathrm{BMI}^{2 / 3} \mathrm{x}\right.$ height $\left.(\mathrm{cm})^{1 / 2}\right],{ }^{36}$ and the waist circumference triglyceride index (WTI) was calculated as the product of WC $(\mathrm{cm})$ multiplied by TG $(\mathrm{mmol} / \mathrm{L}){ }^{37}$ The conicity index $(\mathrm{CI})$ was calculated by the equation: $\mathrm{WC}(\mathrm{cm}) / 10.109 \times$ square root of $\mathrm{BW}(\mathrm{kg}) /$ higher $(\mathrm{m}) .{ }^{38}$ The VAI was calculated using the equation: WC / $[36.58+(1.89 \times \mathrm{BMI})] \times(\mathrm{TG} / 0.81) \times(1.52 /$ HDL-C $),{ }^{39}$ and the lipid accumulation product (LAP) was calculated as (WC (cm)-58) x (TG9mmol)), as established for women. ${ }^{40}$

\section{Biochemical Measurements}

A glucose oxidase technique (Beckman Glucose Analyses, Fullerton, CA, USA) was used to measure fasting glucose. For the oral glucose tolerance test (OGTT), blood samples were collected at $0,30,60,90,120$, and 180 minutes after the ingestion of $75 \mathrm{~g}$ of dextrose for the measurement of plasma glucose and insulin levels. ${ }^{41}$ Glycated hemoglobin was measured using the turbidimetric assay (Wiener Laboratories, Rosario, Argentina). The estimated average glucose (eAG, $\mathrm{mmol} / \mathrm{L}$ ) was calculated using the equation $\mathrm{eAG}=1.5944$ 
multiplied by glycated hemoglobin minus $2.5944 .{ }^{42}$ Homeostatic Model Assessment of Insulin Resistance (HOMA-IR), and basal insulin release ( $\beta$-cell function, HOMA \% B) were calculated using the free HOMA 2 calculator software (Diabetes Trials Unit, Oxford, UK). ${ }^{43}$ Triglycerides (TG), highdensity lipoprotein cholesterol (HDL-C), and total cholesterol (TC) were measured after a 12-hour overnight fast using an enzymatic assay (Wiener Laboratories, Rosario, Argentina). Low-density lipoprotein cholesterol (LDL-C) was calculated as TC - $(\mathrm{HDL}-\mathrm{C}+\mathrm{TG} / 5){ }^{44}$

\section{Hormone Measurements}

Without the requirement of any resting period, blood samples were taken by cubital venipuncture between 7:30 and 10:00 Am, after 10 to 12 hours of fasting, between the $3^{\text {rd }}$ and $5^{\text {th }}$ days of spontaneous menstruation or, in the case of infrequent menses or amenorrhea, on any day regardless of the time elapsed since the last menstrual period; in this case, the progesterone (P4) level was used to certify that samples were collected in the follicular phase and the results were validated whenever the $\mathrm{P} 4$ level was $<6.3 \mathrm{nmol} / \mathrm{L} .{ }^{45,46}$ Thyroid-stimulating hormone, estradiol (E2), PRL, SHBG, total T, DHEA, and FT4 were measured with an electrochemiluminescence assay (Elecsys 1010, Roche Diagnostics GmbH, Mannheim, Germany). Serum P4, A4, DHEAS, cortisol $(\mathrm{F})$, and insulin were measured using a chemiluminescence assay (Advia Centaur, Siemens Healthcare Diagnostics, UK or Siemens Medical Solution Diagnostics, Los Angeles, CA, USA). Free testosterone concentrations were measured using an ELISA kit (GenWay Biotech Inc., San Diego, CA, USA). 17hydroxyprogesterone levels were verified using a coat-acount radioimmunoassay (Siemens Health Care Diagnostics Inc., Los Angeles CA, USA). The precision of these hormone measurements was verified in a recent publication. ${ }^{33}$ The FAI was calculated as $\mathrm{T}(\mathrm{nmol} / \mathrm{L}$ divided by SHBG $(\mathrm{nmol} / \mathrm{L}) \times 100$, and index of hyperandrogenism (IHA) was estimated as fifth root FAI $x$ A4 X DHEA x DHEAS. ${ }^{46}$

\section{Statistical Analysis}

The original data of each variable were initially submitted to the Grubs test to avoid interference of outliers. Distributions of all variables were examined using the Shapiro-Wilk test. Data with asymmetric distribution are presented as numbers and percentages $(\mathrm{n} \%)$, and data with symmetric distribution are shown as mean $(\bar{x})$ and standard deviation (SD). Proportions were compared using the chi-squared test or the Fisher exact test when appropriate. Comparisons of Gaussian variables were performed using one-way analysis of variance (ANOVA). Univariate logistic regression was applied to examine the relationship between anthropometric and metabolic parameters as dependent variables and DHEA, DHEAS, DHEA/T ratio, and DHEAS/T ratios as independent variables. The strength of independent variables in predicting anthropometric and metabolic abnormalities were controlled by age and BMI and given as odds ratio (OR) and $95 \%$ confidence interval $(\mathrm{CI})$. The Kruskal-Wallis test, followed by the Bonferroni post-hoc test, was used in univariate logistic regression. For all univariate logistic regression analyses, the $90^{\text {th }}$ percentile of dependent variables, taken from 425 normalweight non-PCOS controls, was used as a cutoff. ${ }^{9}$ The explained variation in the criterion variable was given by Cox and Snell $R^{2}$ and Nagelkerke $R^{2}$ values. Multivariate forward stepwise logistic regression was done including DHEA, DHEAS, DHEA/T, and DHEAS/T as significant independent variables in the models. Age and BMI were also included to control for confounders. The fit of the logistic regression models was evaluated using the Hosmer-Lemeshow goodness-of-fit test. Receiver operating characteristic (ROC) analysis curves were calculated using DHEA, DHEAS, DHEA/T, and DHEAS/T as independent variables, and significant anthropometric and metabolic variables were used as dependent variables. All tests were two-sided, and p-values $<0.05$ were considered statistically significant. All statistical procedures were performed using SPSS Statistics for Windows, version 17 (SPSS Inc, Chicago, IL, USA).

\section{Results}

Comparisons of age, ethnicity, clinical, and hormone parameters among groups are shown in - Table 1. Most PCOS patients were Caucasians, $72.4 \%$ NA-PCOS and 70.6\% HAPCOS $(p=0.603)$. African descendants were 9.6 and $12.7 \%$ NA-PCOS and HA-PCOS, respectively $(p=0.307)$. Women of other ethnicities were also similar in NA-PCOS and HA-PCOS (18.0 versus $16.0 \%$, respectively, $p=0.711$ ). Among controls, the distribution of these ethnicities was different from that of the PCOS groups: $89.3 \%$ were Caucasians, $60.0 \%$ were African descendants, and $4.7 \%$ were of other races $(p<0.05$ for all comparisons). Comparisons of anthropometric, anthropometric-metabolic indexes, and metabolic characteristics of normal cycling controls, NA-PCOS, and HA-PCOS women are shown in -Supplementary Table S1 (available online only).

\section{The Predictive Role of DHEA in Clinical, Anthropometric, and Metabolic Parameters}

In non-PCOS controls, DHEA had no significant predictive role but tended to predict an increase in $\mathrm{SBP}(\mathrm{OR}=2.47$; $p=0.054$; area under the curve $[\mathrm{AUC}]=0.705 ; p<0.001$ ), and a decrease in eAG $(\mathrm{OR}=0.69 ; p=0.051$; $\mathrm{AUC}=0.700$; $p=0.006$ ) without reaching statistical significance. In NAPCOS (-Table 2), DHEA levels predicted elevation in body weight $(\mathrm{OR}=2.58 ; p=0.039)$, fasting glucose $(\mathrm{OR}=4.36$; $p=0.021)$, and against increase in HOMA \%B $(\mathrm{OR}=0.58$; 0.029). In HA-PCOS, - Table 3, DHEA significantly predicted against the increase in most anthropometric-metabolic indexes ( $O R=0.36-0.97)$. Regarding biochemical markers, DHEA levels predicted against elevation of TG concentrations $(\mathrm{OR}=0.76 ; p=0.006)$.

\section{The Predictive Role of DHEAS in Clinical, Anthropometric, and Metabolic Parameters}

In non-PCOS controls, DHEAS was not associated with any abnormality in anthropometric or anthropometric-metabolic index. Regarding metabolic parameters, DHEAS predicted against increase in eAG $(\mathrm{OR}=0.38 ; p=0.036 ; \mathrm{AUC}=0.706$; 
Table 1 Comparisons of baseline clinical characteristics of normoandrogenemic, hyperandrogenemic, women with polycystic ovary syndrome, and normal cycling controls

\begin{tabular}{|c|c|c|c|}
\hline Variables & Non-PCOS & NA-PCOS & HA-PCOS \\
\hline Age (years old) & $29.9 \pm 4.8^{a}$ & $29.0 \pm 5.2^{a}$ & $27.0 \pm 5.5^{b}$ \\
\hline \multicolumn{4}{|l|}{ Ethnicity $(\mathrm{n}, \%)^{*}$} \\
\hline Caucasian & $267(89.3)^{\mathrm{a}}$ & $113(72.4)^{\mathrm{b}}$ & $335(70.6)^{\mathrm{b}, * *}$ \\
\hline African descendent & $18(6.0)^{\mathrm{a}}$ & $15(9.6)^{\mathrm{a}}$ & $60(12.7)^{\mathrm{b}}$ \\
\hline Other & $14(4.7)^{\mathrm{a}}$ & $28(18.0)^{\mathrm{b}}$ & $79(16.7)^{\mathrm{b}}$ \\
\hline \multicolumn{4}{|c|}{ Blood pressure $(\bar{x} \pm S D)^{* * *}$} \\
\hline $\mathrm{SBP}(\mathrm{mmHg})$ & $113.1 \pm 9.5^{\mathrm{a}}$ & $116.6 \pm 72.1^{\mathrm{b}}$ & $120.0 \pm 12.4^{b}$ \\
\hline DBP $(\mathrm{mmHg})$ & $71.4 \pm 9.0^{\mathrm{a}}$ & $74.6 \pm 9.3^{b}$ & $76.2 \pm 9.3^{b}$ \\
\hline \multicolumn{4}{|l|}{ Clinical signs $(n, \%)^{*}$} \\
\hline Acne & $12(4.0)^{\mathrm{a}}$ & $70(44.9)^{\mathrm{b}}$ & $217(45.7)^{\mathrm{b}}$ \\
\hline Hirsutism & $7(2.3)^{\mathrm{a}}$ & $72(46.2)^{b}$ & $224(47.3)^{\mathrm{b}}$ \\
\hline Acanthosis & $2(0.7)^{a}$ & $27(17.3)^{b}$ & $95(20.0)^{\mathrm{b}}$ \\
\hline Striae & $0(0.0)^{a}$ & $19(12.2)^{b}$ & $70(14.7)^{\mathrm{b}}$ \\
\hline Galactorrhea & $0(0.0)^{\mathrm{a}}$ & $2(1.3)^{\mathrm{b}}$ & $6(1.3)^{\mathrm{b}}$ \\
\hline \multicolumn{4}{|l|}{ Metabolic disorders* } \\
\hline IFG & $8(2.6)^{a}$ & $8(5.1)^{b}$ & $62(13.1)^{c}$ \\
\hline $\mathrm{Gl}$ & $11(3.7)^{\mathrm{a}}$ & $16(6.9)^{\mathrm{b}}$ & $78(26.3)^{c}$ \\
\hline T2DM & $10(3.3)^{\mathrm{NS}}$ & $5(5.0)^{\mathrm{NS}}$ & $18(6.0)^{\mathrm{NS}}$ \\
\hline \multicolumn{4}{|l|}{ Hormones* } \\
\hline DHEAS > 34nmol/l & $32(10.7)^{a}$ & $8(5.1)^{a}$ & $32(6.8)^{a}$ \\
\hline DHEAS $>6.6 \mu \mathrm{l} / \mathrm{l}$ & $29(9.7)^{a}$ & $1(0.6)^{\mathrm{a}}$ & $144(31.8)^{\mathrm{b}}$ \\
\hline $\mathrm{T}>1.75 \mathrm{mmol} / \mathrm{l}$ & $30(10.0)^{\mathrm{a}}$ & $11(7.1)^{\mathrm{a}}$ & $328(70.4)^{b}$ \\
\hline $\mathrm{FAI}>5.2$ & $12(4.0)^{\mathrm{a}}$ & $19(12.2)^{b}$ & $260(61.3)^{c}$ \\
\hline
\end{tabular}

Abbreviations: DBP, diastolic blood pressure; DHEAS, dehydroepiandrosterone sulfate; DM, diabetes mellitus; FAI, free androgen index; Gl, glucose intolerance; HA-PCOS, hyperandrogenemic polycystic ovary syndrome; IFG, impaired fasting glucose; NA-PCOS, normoandrogenemic polycystic ovary syndrome; SBP, systolic blood pressure; T, testosterone.

${ }^{*}$ Comparisons using chi-squared or Fisher tests as appropriate.

**Equal subscript letter denotes proportions that do not differ significantly from each other at the level of 0.05 ; otherwise, different letters indicate $p<0.05$ between proportions or means \pm standard deviation. $N S=$ not significant.

${ }^{* * *}$ Comparisons using one-way analysis of variance.

$p=0.001)$. In NA-PCOS women, DHEAS only predicted against increase in WHR $(\mathrm{OR}=0.59 ; p=0.042$; $\mathrm{AUC}=0.757$; $p=0.002)$. In HA-PCOS, DHEAS concentrations predicted against elevation in the $\mathrm{CI}(\mathrm{OR}=0.31 ; p=0.028$; $\mathrm{AUC}$ $=0.740 ; p<0.001)(-$ Table 3$)$.

\section{The Predictive Role of DHEA/total Testosterone Ratio in Clinical, Anthropometric, and Metabolic Parameters}

The DHEA/total testosterone ratio (DHEA/T) was a good predictor against increase in WHR $(\mathrm{OR}=0.44 ; p=0.015$; AUC $=0.662 ; p<0.001)$ in the control group. In NA-PCOS women, the DHEA/T ratio tended to predict against increase in $\mathrm{BW}(\mathrm{OR}=0.95 ; p=0.071 ; \mathrm{AUC}=0.974 ; p<0.001)$, and decrease in C-pep levels $(\mathrm{OR}=0.68 ; p=0.070$; $\mathrm{AUC}=0.805$; $p<0.001)$. This ratio predicted increase in fasting glucose $(\mathrm{OR}=2.65 ; p=0.018 ; \mathrm{AUC}=0.915 ; p<0.001)$. In HA-PCOS women ( - Table 4 ), the DHEA/T ratio predicted against increase in WTI $(\mathrm{OR}=0.70 ; p=0.003), \mathrm{CI} \quad(\mathrm{OR}=0.79$; $p=0.036), \quad$ BSI $\quad(\mathrm{OR}=0.77 ; p=0.046), \quad \mathrm{VAI} \quad(\mathrm{OR}=0.76$; $p=0.039$ ), and LAP (OR $=0.76 ; p=0.032$ ). However, with statistical significance, the DHEA/T ratio predicted against increase in TC $(\mathrm{OR}=0.76 ; p=0.033)$, in VLDL-C $(\mathrm{OR}=0.90$; $p=0.049)$, and in TG $(\mathrm{OR}=0.72 ; p=0.006)$.

\section{The Predictive Role of DHEAS/Total Testosterone Ratio in Clinical, Anthropometric, and Metabolic Parameters}

In non-PCOS controls (-Table 5), the DHEAS/T ratio predicted only against the increase in WHR $(O R=0.44$; $p=0.015 ;$ AUC $=0.663 ; p<0.001)$. In NA-PCOS, the DHEAS/ $\mathrm{T}$ ratio did not predict any biomarker of anthropometric or metabolic abnormalities. In the HA-PCOS group, the DHEAS/T ratio predicted against increase in $\mathrm{CI}(\mathrm{OR}=0.29$; $p=0.007 ;$ AUC $=0.738 ; p<0.001)$, and in $\mathrm{TC}(\mathrm{OR}=0.37$; $p=0.041 ; A U C=0.655 ; p=0.001)$. Without reaching statistical significance, this ratio also tended to predict against increase in VLDL-C $(\mathrm{OR}=0.87 ; p=0.084 ; \quad \mathrm{AUC}=0.570$; 
Table 2 Age and body mass index controlled univariate logistic regression between clinical, anthropometric, anthropometricmetabolic indexes, and metabolic biomarkers as dependent variables, and dehydroepiandrosterone as the independent variable in normoandrogenemic women with polycystic ovary syndrome

\begin{tabular}{|c|c|c|c|c|c|c|}
\hline Variable & B & Wald & Sig & Exp B (Lower-Upper) & AUC & p-value \\
\hline $\mathrm{SBP}(\mathrm{mmHg})$ & -0.424 & 1.761 & 0.184 & $0.655(0.350-1.224)$ & 0.842 & $<0.001$ \\
\hline $\mathrm{DBP}(\mathrm{mmHg})$ & -0.222 & 0.286 & 0.593 & $0.801(0.355-1.808)$ & 0.757 & 0.006 \\
\hline BW (kg) & 0.950 & 4.247 & 0.039 & $2.584(1.048-6.372)$ & 0.976 & $<0.001$ \\
\hline WC $(\mathrm{cm})$ & -0.206 & 0.385 & 0.535 & $0.814(0.424-1.560)$ & 0.957 & $<0.001$ \\
\hline WHR (ratio) & -0.295 & 0.627 & 0.429 & $0.745(0.359-1.545)$ & 0.697 & 0.019 \\
\hline $\mathrm{FM}(\mathrm{kg})$ & 0.592 & 1.033 & 0.309 & $1.808(0.577-5.667)$ & 0.991 & $<0.001$ \\
\hline FM (\%) & 0.640 & 1.286 & 0.257 & $1.826(0.628-5.726)$ & 0.989 & $<0.001$ \\
\hline FM/LBM (ratio) & 0.172 & 0.163 & 0.686 & $1.194(0.505-2.824)$ & 0.980 & $<0.001$ \\
\hline WTI & -0.107 & 0.169 & 0.681 & $0.898(0.835-1.499)$ & 0.789 & $<0.001$ \\
\hline $\mathrm{Cl}(\%, \mathrm{pg} / \mathrm{ml}, \mathrm{nmol} / \mathrm{L})$ & -0.262 & 1.089 & 0.297 & $0.770(0.471-1.258)$ & 0.748 & $<0.001$ \\
\hline BSI & -0204 & 1.043 & 0.307 & $0.816(0.552-1.206)$ & 0.600 & 0.041 \\
\hline VAl & 0.242 & 0.689 & 0.407 & $1.274(0.719-2.257)$ & 0.734 & $<0.001$ \\
\hline LAP (cm, mmol/L) & -0.424 & 2.008 & 0.157 & $0.654(0.364-1.177)$ & 0.885 & $<0.001$ \\
\hline Go (mmol/L) & 1.473 & 5.321 & 0.021 & $4.363(1.248-15.257)$ & 0.924 & $<0.001$ \\
\hline lo $(\mathrm{pmol} / \mathrm{L})$ & -0.069 & 3.742 & 0.053 & $0.9336(0.820-1.001)$ & 0.838 & $<0.001$ \\
\hline C-pep (pmol/L) & -0.455 & 3.182 & 0.074 & $0.635(0.385-1.046)$ & 0.780 & $<0.001$ \\
\hline HOMA-IR & 0.095 & 0.089 & 0.766 & $1.100(0.582-1.063)$ & 0.784 & $<0.001$ \\
\hline HOMA \%B & -0.544 & 4.740 & 0.029 & $0.581(0.356-0.947)$ & 0.739 & $<0.001$ \\
\hline eAG (mmol/L) & -0.075 & 0.089 & 0.765 & $0.928(0.567-1.518)$ & 0.638 & 0.027 \\
\hline $\mathrm{TC}(\mathrm{mmol} / \mathrm{L})$ & 0.010 & 0.001 & 0.971 & $1.010(0.576-1.771)$ & 0.554 & 0.293 \\
\hline $\mathrm{HDL}-\mathrm{C}(\mathrm{mmol} / \mathrm{L})$ & -0.025 & 0.793 & 0.373 & $0.975(0.922-1.031)$ & 0.700 & $<0.001$ \\
\hline LDL-C (mmol/L) & -0.135 & 0.255 & 0.613 & $0.874(0.519-1.473)$ & 0.552 & 0.431 \\
\hline VLDL-C (mmol/L) & 0.009 & 0.054 & 0.816 & $1.009(0.937-1.086)$ & 0.732 & $<0.001$ \\
\hline TG (mmol/L) & 0.025 & 0.567 & 0.452 & $1.026(0.960-1.096)$ & 0.722 & $<0.001$ \\
\hline DM & -0.072 & 0.517 & 0.472 & $0.931(0.765-1.132)$ & 0.868 & 0.006 \\
\hline IG & 0.019 & 0.134 & 0.714 & $1.019(0.920-1.129)$ & 0.820 & $<0.001$ \\
\hline
\end{tabular}

Abbreviations: SBP, systolic blood pressure; DBP, diastolic blood pressure; BW, body weight; WC, waist circumference; WHR, waist-hip ratio; FM, fat mass; LBM, lean body mass; WTI, waist circumference-triglyceride index; Cl, conicity index; BSI, body shape index; VAI; visceral adiposity index; LAP, lipid accumulation product; Go, fasting glucose; lo, fasting insulin; C-pep, C-peptide; HOMA-IR,homeostatic assessment model of insulin resistance; HOMA\%B, homeostatic model assessment of $\beta$-cell function; eAG, average glucose; TC, total cholesterol; HDL-C, high-density lipoprotein cholesterol; LDL-C, low-density lipoprotein cholesterol; VLDL-C, very-low-density lipoprotein cholesterol; TG, triglyceride; DM, diabete mellitus; IG, intolerance glucose.

$p<0.001)$, and in WTI $(\mathrm{OR}=0.64 ; p=0.067 ; \mathrm{AUC}=0.719$; $p<0.001)$.

\section{Multivariate Logistic Regression Analysis}

Multivariate logistic regression models, consistent with univariate regression, retained the predictive role of the DHEAS/T ratio against increase in WHR $(\mathrm{OR}=0.44$; $p=0.016)$ and of DHEAS against increase in eAG $(\mathrm{OR}=0.36$; $p=0.029)$ in the non-PCOS control group. In NA-PCOS women, the results of the univariate regression were maintained after multiple regression. Thus, DHEA maintained the predictive role favoring increase in $\mathrm{BW}(\mathrm{OR}=2.60 ; p=0.019)$. In these women, DHEA also predicted against the increase in HOMA \%B $(\mathrm{OR}=0.34 ; p=0.039)$. The DHEA/T ratio favors an increase in fasting glucose $(\mathrm{OR}=2.60 ; p=0.019)$. In HAPCOS, DHEA maintained prediction against the increase in $\operatorname{VAI}(\mathrm{OR}=0.74 ; p=0.006)$ and in TG $(\mathrm{OR}=0.74 ; p=0.002)$.
The DHEAS/T ratio predicted against the increase in TC $(\mathrm{OR}=0.30 ; p=0.005)$; nevertheless, the DHEAS/T ratio favors an increase in $\mathrm{CI}(\mathrm{OR}=1.54 ; p=0.004)$. The DHEA/T ratio predicted against an increase in $\mathrm{WTI}(\mathrm{OR}=0.70$; $p=0.004)$ and in $\operatorname{LAP}(\mathrm{OR}=0.76 ; p=0.038)$.

\section{Discussion}

Many studies have investigated the role of adrenal androgens in PCOS. There have been attempts to translate basic knowledge into the clinical practice. The present study evaluated the strength of adrenal androgens in predicting blood pressure, anthropometric, and metabolic abnormalities in women with PCOS, after separating PCOS women with normal from high androgens in the blood. The impact of DHEA, DHEAS, and the ratios of these prohormones and total testosterone were considered because between $\sim 70$ and 
Table 3 Age and body mass index controlled univariate logistic regression between clinical, anthropometric, anthropometricmetabolic indexes, and metabolic biomarkers as dependent variables, and dehydroepiandrosterone as the independent variable in hyperandrogenemic women with polycystic ovary syndrome

\begin{tabular}{|c|c|c|c|c|c|c|}
\hline Variable & B & Wald & Sig & Exp B (Lower-Upper) & AUC & p-value \\
\hline $\mathrm{SBP}(\mathrm{mmHg})$ & 0.059 & 0.327 & 0.567 & $1.061(0.866-1.300)$ & 0.773 & $<0.001$ \\
\hline $\mathrm{DBP}(\mathrm{mmHg})$ & -0.098 & 0.559 & 0.455 & $0.907(0.702-1.171)$ & 0.751 & $<0.001$ \\
\hline BW (kg) & 0.003 & 0.001 & 0.978 & $1.003(0.794-1.268)$ & 0.947 & $<0.001$ \\
\hline WC $(\mathrm{cm})$ & -1.072 & 2.968 & 0.085 & $0.342(1.101-1.159)$ & 0.957 & $<0.001$ \\
\hline WHR & -0.189 & 2.429 & 0.119 & $0.828(0.652-1.050)$ & 0.730 & $<0.001$ \\
\hline FM $(k g)$ & 0.103 & 0.461 & 0.497 & $1.108(0.824-1.491)$ & 0.987 & $<0.001$ \\
\hline FM (\%) & 0.013 & 0.008 & 0.929 & $1.013(0.767-1.336)$ & 0.977 & $<0.001$ \\
\hline FM/LBM (ratio) & -0.005 & 0.001 & 0.976 & $0.995(0.711-1.392)$ & 0.986 & $<0.001$ \\
\hline WTI (WC/TG) & -0.227 & 5.256 & 0.022 & $0.797(0.656-0.968)$ & 0.803 & $<0.001$ \\
\hline $\mathrm{Cl}(\%, \mathrm{pg} / \mathrm{ml}, \mathrm{nmol} / \mathrm{L})$ & -0.841 & 0.3178 & 0.049 & $0.451(0.187-0.996)$ & 0.742 & $<0.001$ \\
\hline BSI & -0.274 & 11.388 & 0.001 & $0.761(0.649-0.892)$ & 0.601 & $<0.001$ \\
\hline VAI & -0.999 & 4.204 & 0.040 & $0.369(0.142-0.957)$ & 0.726 & $<0.001$ \\
\hline LAP (cm, mmol/L) & -0.024 & 3.971 & 0.046 & $0.976(0.954-1.000)$ & 0.886 & $<0.001$ \\
\hline Go $(\mathrm{mmol} / \mathrm{L})$ & 0.676 & 1.302 & 0.254 & $1.966(0.616-6.282)$ & 0.708 & $<0.001$ \\
\hline lo (pmol/L) & 0.175 & 0.161 & 0.688 & $1.192(0.506-2.084)$ & 0.785 & $<0.001$ \\
\hline C-pep (nmol/L) & -0.138 & 1.815 & 0.178 & $0.871(0.713-1.065)$ & 0.832 & $<0.001$ \\
\hline HOMA-IR & 0.065 & 0.017 & 0.897 & $1.067(0.397-2.866)$ & 0.774 & $<0.001$ \\
\hline HOMA \%B & 0.133 & 0.098 & 0.755 & $1.143(0.495-2.638)$ & 0.701 & $<0.001$ \\
\hline eAG (mmol/L) & -0.022 & 0.055 & 0.814 & $0.978(0.812-1.178)$ & 0.699 & $<0.001$ \\
\hline $\mathrm{TC}(\mathrm{mmol} / \mathrm{L})$ & 0.145 & 0.096 & 0.752 & $1.156(0.461-2.898)$ & 0.630 & $<0.001$ \\
\hline $\mathrm{HDL}-\mathrm{C}(\mathrm{mmol} / \mathrm{L})$ & 0.442 & 1.094 & 0.296 & $1.556(0.679-3.565)$ & 0.688 & $<0.001$ \\
\hline LDL-C (mmol/L) & 0.084 & 0.035 & 0.852 & $0.919(0.378-2.233)$ & 0.602 & 0.002 \\
\hline VLDL-C (mmol/L) & -0.074 & 0.492 & 0.483 & $0.928(0.755-1.142)$ & 0.698 & $<0.001$ \\
\hline TG (mmol/L) & -0.270 & 0.748 & 0.006 & $0.763(0.629-0.926)$ & 0.740 & $<0.001$ \\
\hline DM & -0.212 & 0.836 & 0.361 & $0.809(0.513-1.278)$ & 0.812 & $<0.001$ \\
\hline IG & 0.175 & 2.265 & 0.132 & $1.192(0.948-1498)$ & 0.732 & $<0.001$ \\
\hline
\end{tabular}

Abbreviations: SBP, systolic blood pressure; DBP, diastolic blood pressure; BW, body weight; WC, waist circumference; WHR, waist-hip ratio; FM, fat mass; LBM, lean body mass; WTI, waist circumference-triglyceride index; CI, conicity index; BSI, body shape index; VAl; visceral adiposity index; LAP, lipid accumulation product; Go, fasting glucose; Io, fasting insulin; C-pep, C-peptide; HOMA-IR, homeostatic assessment model of insulin resistance; HOMA\%B, homeostatic model assessment of $\beta$-cell function; eAG, average glucose; TC, total cholesterol; HDL-C, high-density lipoprotein cholesterol; LDL-C, low-density lipoprotein cholesterol; VLDL-C, very-low-density lipoprotein cholesterol; TG, triglyceride; DM, diabete mellitus; IG, intolerance glucose.

95\% of DHEA and DHEAS molecules have the adrenal gland as a primary source. ${ }^{26}$ Either in a combination of various androgens or in the elevation of at least one androgen, biochemical hyperandrogenism is found in $>70 \%$ of women with PCOS. ${ }^{46,47}$ Higher androgens of the adrenal source are reported in between 20 and $30 \%$ of PCOS women. ${ }^{48,49}$ Insulin resistance is a common comorbidity of hyperandrogenemic PCOS through decreased insulin-like growth factor 1 (IGF$\mathrm{BP})$ leading to increased free insulin-like growth factor 1 (IGF-1), which stimulates ovarian androgen production. ${ }^{50}$ The role of insulin resistance in the adrenal function of PCOS women is unclear. ${ }^{51}$ Conversely, the cross-talk between adrenal androgens and insulin acting in women with PCOS is of clinical relevance. Furthermore, while insulin is higher in obesity, cortisol (F), DHEA, and DHEAS appear to be lower. ${ }^{52}$

The incidence of $75 \%$ of biochemical hyperandrogenism in women with PCOS in the present study is in agreement with other studies. ${ }^{53-55}$ As shown in - Table 1, the slightly higher SBP and DBP levels in PCOS than in controls, observed mainly in the hyperandrogenemic group, found in the present study, also endorse previous findings. ${ }^{56-58}$ In the same way, a higher prevalence of glucose intolerance in women with PCOS has been extensively found. ${ }^{7,13,45,59,60}$ The finding that, in NA-PCOS, DHEA was negatively correlated with body weight, fasting glucose, and $\beta$-cell activity, indicates a protective role of DHEA against adiposity and insulin resistance. In previous studies, DHEA has been shown to inhibit the proliferation and differentiation of adipocytes in the subcutaneous adipose tissue compartment (SAT) and to increase adipocyte glucose uptake in this location. ${ }^{21,61} \mathrm{Ad}-$ ditionally, DHEA appears to inhibit adipogenesis in omental adipocytes through an increase in resistin production. ${ }^{20,62}$ Dehydroepiandrosterone also increases insulin signaling to its secretion and protects against omental adipogenesis. ${ }^{63}$ 
Table 4 Age and body mass controlled univariate logistic regression between clinical, anthropometric, and anthropometricmetabolic indexes as dependent variables, and dehydrotestosterone/testosterone ratio as the independent variable in hyperandrogenic women with polycystic ovary syndrome

\begin{tabular}{|c|c|c|c|c|c|c|}
\hline Variable & B & Wald & Sig & Exp B (Lower-Upper) & AUC & p-value \\
\hline $\mathrm{SBP}(\mathrm{mmHg})$ & 0.279 & 0.387 & 0.568 & $1.323(0.508-3.441)$ & 0.773 & $<0.001$ \\
\hline $\mathrm{DBP}(\mathrm{mmHg})$ & 0.130 & 0.048 & 0.826 & $1.138(0.357-3.627)$ & 0.742 & $<0.001$ \\
\hline BW (kg) & 0.058 & 0.009 & 0.924 & $1.060(0.320-3.500)$ & 0.947 & $<0.001$ \\
\hline$W C(\mathrm{~cm})$ & -0.146 & 0.954 & 0.329 & $0.864(0.645-1.158)$ & 0.957 & $<0.001$ \\
\hline WHR (ratio) & -0.195 & 1.779 & 0.182 & $0.823(0.618-1.096)$ & 0.722 & $<0.001$ \\
\hline $\mathrm{FM}(\mathrm{kg})$ & 0.013 & 0.005 & 0.944 & $1.013(0.709-1.447)$ & 0.987 & $<0.001$ \\
\hline $\mathrm{FM}(\%)$ & 0.342 & 0.225 & 0.636 & $1.408(0.342-5.792)$ & 0.978 & $<0.001$ \\
\hline WTI (ratio) & -0.355 & 8.615 & 0.003 & $0.701(0.553-0.889)$ & 0.809 & $<0.001$ \\
\hline $\mathrm{Cl}(\%, \mathrm{pg} / \mathrm{ml}, \mathrm{nmol} / \mathrm{L})$ & -0.227 & 4.406 & 0.036 & $0.797(0.645-0.985)$ & 0.739 & $<0.001$ \\
\hline BSI (ratio) & -0.252 & 3.988 & 0.046 & $0.777(0.607-0.995)$ & 0.888 & $<0.001$ \\
\hline VAI & -0.267 & 4.276 & 0.039 & $0.766(0.594-0.986)$ & 0.723 & $<0.001$ \\
\hline LAP (cm, mmol/L) & -0.275 & 4.624 & 0.032 & $0.760(0.591-0.976)$ & 0.888 & $<0.001$ \\
\hline Go $(\mathrm{mmol} / \mathrm{L})$ & -0.032 & 1.773 & 0.183 & $0.968(0.923-1.015)$ & 0.703 & $<0.001$ \\
\hline lo (pmol/L) & -0.014 & 0.016 & 0.898 & $0.987(0.803-1.273)$ & 0.783 & $<0.001$ \\
\hline HOMA-IR & -0.492 & 0.946 & 0.331 & $0.611(0.227-1.648)$ & 0.775 & $<0.001$ \\
\hline HOMA \%B & 0.387 & 0.800 & 0.371 & $1.472(0.632-3.437)$ & 0.694 & $<0.001$ \\
\hline C-pep (nmol/L) & -0.028 & 2.464 & 0.116 & $0.972(0.938-1.007)$ & 0.838 & $<0.001$ \\
\hline eAG (mmol/L) & -0.561 & 1.544 & 0.214 & $0.571(0.235-1.303)$ & 0.719 & $<0.001$ \\
\hline $\mathrm{TC}(\mathrm{mmol} / \mathrm{L})$ & -0.216 & 4.168 & 0.033 & $0.766(0.600-0.962)$ & 0.652 & $<0.001$ \\
\hline $\mathrm{HDL}-\mathrm{C}(\mathrm{mmol} / \mathrm{L})$ & -0.046 & 0.204 & 0.652 & $0.955(0.783-1.166)$ & 0.689 & $<0.001$ \\
\hline VLDL-C (mmol/L) & -0.040 & 3.888 & 0.049 & $0.961(0.923-1.000)$ & 0.705 & $<0.001$ \\
\hline $\mathrm{TG}(\mathrm{mmol} / \mathrm{L})$ & -0.738 & 7.629 & 0.006 & $0.720(0.920-0.909)$ & 0.740 & $<0.001$ \\
\hline LDL-C (mmol/L) & -0.115 & 1.007 & 0.316 & $0.891(0.711-1.116)$ & 0.611 & $<0.001$ \\
\hline DM & -0.091 & 2.495 & 0.114 & $0.913(0.815-1.022)$ & 0.849 & $<0.001$ \\
\hline IG & -0.059 & 0.010 & 0.918 & $0.943(0.306-2.909)$ & 0.735 & $<0.001$ \\
\hline
\end{tabular}

Abbreviations: SBP, systolic blood pressure; DBP, diastolic blood pressure; BW, body weight; WC, waist circumference; WHR, waist-hip ratio; FM, fat mass; WTI, waist circumference-triglyceride index; $\mathrm{Cl}$, conicity index; BSI, body shape index; VAl; visceral adiposity index; LAP, lipid accumulation product; Go, fasting glucose; lo, fasting insulin; HOMA-IR, homeostatic assessment model of insulin resistance; HOMA\%B, homeostatic model assessment of $\beta$-cell function; C-pep, C-peptide; eAG, average glucose; TC, total cholesterol; HDL-C, high-density lipoprotein cholesterol; VLDL-C, very-low-density lipoprotein cholesterol; TG, triglyceride; LDL-C, low-density lipoprotein cholesterol; DM, diabete mellitus; IG, intolerance glucose.

Furthermore, DHEA suppresses the activity and expression of glucose-6-phosphate and of phosphoenol carboxykinase, decreasing gluconeogenesis and increasing glucose uptake in the adipocyte and hepatocyte. ${ }^{64}$ Clinical biomarkers of central adiposity were not correlated with DHEA concentrations in the present study in normoandrogenemic women with PCOS.

On the other hand, in HA-PCOS women, DHEA was negatively correlated with various anthropometric-metabolic indexes and TG abnormalities. Thus, the present study supports the knowledge of the beneficial role of DHEA levels in women with PCOS, at least in those with high androgen levels. ${ }^{18,65}$ Both in vitro and in vivo studies have shown a protective role of DHEA in the cardiovascular system. ${ }^{66}$ Furthermore, lower levels of DHEA are associated with increased body fat accumulation. ${ }^{67}$ In contrast, high levels of DHEA are associated with lower BMI, ${ }^{68}$ lower body fat accumulation, and lower risk of T2DM. ${ }^{69,70}$ An antiathero- genic effect of DHEA through inhibition of fibroblast growth, improvement of lipid profile, and decrease of platelet aggregation has also been shown. ${ }^{71}$ It is worthy of note that lower levels of DHEA are found in hyperinsulinemic status due to its diminished synthesis or increased metabolic clearance. Additionally, high levels of glucose and insulin might impair DHEA synthesis in the adrenal gland. ${ }^{72}$

In PCOS, as a whole group, high levels of DHEAS have been found in between 18 and 72\%. 25,59,73,74 The high levels of DHEAS have also been associated with a favorable metabolic and cardiovascular profile. ${ }^{74-78}$ DHEAS opposes $\mathrm{T}$ action concerning the risk of obesity, and IR. ${ }^{25}$ High levels of DHEAS are associated with lower BMI $^{68}$ when compound with controls and its levels decrease after weight loss after bariatric surgery. ${ }^{79}$ Dehydroepiandrosterone sulfate levels have been negatively correlated with WC, WHR, LDL-C, and TG concentrations, adjusted for the confounding effects of age and BMI. ${ }^{74,78}$ Furthermore, DHEAS levels were 
Table 5 Final models of multivariate logistic regression analysis between anthropometric, anthropometric-metabolic, and metabolic indexes it is dependent variables and androgens as independent variables in non-polycystic ovary syndrome controls and women with polycystic ovary syndrome

\begin{tabular}{|c|c|c|c|c|c|c|c|}
\hline Dependent variables & $\begin{array}{l}\text { Retained independent } \\
\text { variables }\end{array}$ & B & Wald & $\mathbf{P}$ & Exp B (Lower-Upper) & AUC & p-value \\
\hline \multicolumn{8}{|l|}{ Non-PCOS } \\
\hline WHR (ratio) & DHEAS/T & -0.8113 & 5.857 & 0.016 & $0.444(0.230-0.857)$ & 0.663 & $<0.001$ \\
\hline eAG (mmol/L) & DHEAS & -1.881 & 4.848 & 0.028 & $0.152(0.145-0.903)$ & 0.704 & 0.001 \\
\hline \multicolumn{8}{|l|}{ NA-PCOS } \\
\hline BW (kg) & DHEA & 0.979 & 4.360 & 0.037 & $2.662(1.062-6.672)$ & 0.977 & $<0.001$ \\
\hline Go (mmol/L) & $\mathrm{DHEA} / \mathrm{T}$ & 0.957 & 5.498 & 0.019 & $2.605(1.170-5.800)$ & 0.906 & $<0.001$ \\
\hline HOMA \%B & DHEA & -0.543 & 4.277 & 0.039 & $0.581(0.348-0.972)$ & 0.739 & $<0.001$ \\
\hline \multicolumn{8}{|l|}{ HA-PCOS } \\
\hline WTI (ratio) & DHEA/T & -0.350 & 8.263 & 0.004 & $0.705(0.555-0.895)$ & 0.809 & $<0.001$ \\
\hline $\mathrm{Cl}(\%, \mathrm{pg} / \mathrm{ml}, \mathrm{nmol} / \mathrm{L})$ & DHEAS/T & 0.434 & 8.405 & 0.004 & $1.544(1.151-2.071)$ & 0.759 & $<0.001$ \\
\hline VAl & DHEA & -0.299 & 7.511 & 0.006 & $0.741(0.599-1.136)$ & 0.719 & $<0.001$ \\
\hline $\mathrm{LAP}(\mathrm{cm}, \mathrm{mmol} / \mathrm{L})$ & DHEA/T & -0.265 & 4.291 & 0.038 & $0.767(0.597-0.986)$ & 0.888 & $<0.001$ \\
\hline $\mathrm{TC}(\mathrm{mmol} / \mathrm{L})$ & DHEAS/T & -1.189 & 8.037 & 0.005 & $0.305(0.134-0.693)$ & 0.666 & $<0.001$ \\
\hline TG (mmol/L) & DHEA & -0.300 & 9.380 & 0.002 & $0.741(0.611-0.897)$ & 0.739 & $<0.001$ \\
\hline
\end{tabular}

Abbreviations: Non-PCOS, not polycystic ovary syndrome; WHR, waist-hip ratio; eAG, average glucose; NA-PCOS, normoandrogenemic polycystic ovary syndrome; BW, body weight; Go, fasting glucose; HOMA\%B, homeostatic model assessment of $\beta$-cell function; HA-PCOS $\beta$ hyperandrogenemic polycystic ovary syndrome; WTI, waist circumference-triglyceride index; $\mathrm{Cl}$, conicity index; VAI; visceral adiposity index; LAP, lipid accumulation product; TC, total cholesterol; TG, triglyceride.

negatively correlated with carotid intima-media thickness ${ }^{75}$ and improved endothelial function. ${ }^{80}$ The predictive value of DHEAS against abnormalities in WHR and in the $\mathrm{Cl}$ of women with PCOS seen in the present study supports its beneficial effect on predicting anthropometric and metabolic derangements. $^{25,74,81,82}$

The DHEA/Tratio was reported to be strongly associated with insulin sensitivity. ${ }^{63}$ However, there is an inconsistent correlation between the DHEAS/T ratio, insulin levels, and insulin receptor binding. ${ }^{83}$ In the clinical practice, this ratio has been used for the prediction and early diagnosis of metabolic syndrome and it appears to antagonize the effect of $\mathrm{T}$ in women with PCOS, which is associated with a favorable metabolic profile. ${ }^{25,84}$ Furthermore, this ratio has been negatively correlated with lower BMI, lower WC, lower WHR, lower TG, lower LDL-C, and higher HDL-C, insulin levels, and HOMA-IR. ${ }^{76-78}$ It also appears that the DHEA/T ratio improves lipid metabolism. ${ }^{84-88}$ The present study supports the knowledge that the DHEA/T ratio predicts various abnormalities in anthropometricmetabolic indexes in PCOS women with biochemical hyperandrogenism and against the increase in fasting glucose despite normal androgens in the blood. Nevertheless, the predictive effect of DHEAS/T against anthropometric and metabolic abnormalities in PCOS is limited.

A few limitations must be considered in the analysis of the present study. The cross-sectional design does not allow to determine causal effects; instead, it provides associations or predictions. The assays used may have some imprecision, but they have presented a good correlation with the gold-standard high-performance liquid chromatography-tandem mass spectrometry assays. ${ }^{89,90}$ The sample size, a clear definition for normoandrogenemic and hyperandrogenemic groups of women with PCOS, and their analysis in separate are the principal strengths of the present study.

\section{Conclusion}

Dehydroepiandrosterone has been demonstrated to be a better predictor of abnormal anthropometric and biochemical parameters in women with PCOS than DHEAS, particularly in hyperandrogenemic women. The DHEA/T ratio has also shown increased prediction to predict against increase in anthropometric and metabolic parameters in PCOS. Dehydroepiandrosterone measurement seems to be preferred in PCOS management. In general, in the clinical practice, it must be highlighted that the predictive and protective effects of both adrenal hormones DHEA and DHEAS are mild or weak.

\section{Contributions}

Medeiros S. F.: design, data description, statistical analysis, and writing of the manuscript; Medeiros M. A. S.: data search, revision of the manuscript; Barbosa B. B.: data search, data analysis, revision of the manuscript; Medeiros A. K. L. W. Y.: data search, revision of the manuscript. Yamamoto M. M. W.: data search, revision of the manuscript. All authors approved the final version of the manuscript.

\section{Conflict of Interests}

The authors have no conflict of interests to declare. 


\section{Acknowledgments}

The authors are grateful to Philip Lindeman, MD, Ph.D., Liberty Medical Communications, for the revision of the English version of the present manuscript.

\section{References}

1 March WA, Moore VM, Willson KJ, Phillips DI, Norman RJ, Davies MJ. The prevalence of polycystic ovary syndrome in a community sample assessed under contrasting diagnostic criteria. Hum Reprod. 2010;25(02):544-551. Doi: 10.1093/humrep/dep399

2 Zawadski JK, Dunaif A. Diagnostic criteria for polycystic ovary syndrome: towards a rational approach. In: Dunaif A, Givens JR, Haseltine F, eds. Polycystic ovary syndrome. Boston: Blackwell Scientific; 1992:377-384

3 Rotterdam ESHRE/ASRM-Sponsored PCOS Consensus Workshop Group. Revised 2003 consensus on diagnostic criteria and longterm health risks related to polycystic ovary syndrome. Fertil Steril. 2004;81(01):19-25. Doi: 10.1016/j.fertnstert.2003.10.004

4 Azziz R, Carmina E, Dewailly D, Diamanti-Kandarakis E, EscobarMorreale HF, Futterweit W, et al; Androgen Excess Society. Positions statement: criteria for defining polycystic ovary syndrome as a predominantly hyperandrogenic syndrome: an Androgen Excess Society guideline. J Clin Endocrinol Metab. 2006;91 (11):4237-4245. Doi: 10.1210/jc.2006-0178

5 Jones H, Sprung VS, Pugh CJ, Daousi C, Irwin A, Aziz N, et al. Polycystic ovary syndrome with hyperandrogenism is characterized by an increased risk of hepatic steatosis compared to nonhyperandrogenic PCOS phenotypes and healthy controls, independent of obesity and insulin resistance. J Clin Endocrinol Metab. 2012;97(10):3709-3716. Doi: 10.1210/ jc.2012-1382

6 Baranova A, Tran TP, Afendy A, Wang L, Shamsaddini A, Mehta R, et al. Molecular signature of adipose tissue in patients with both non-alcoholic fatty liver disease (NAFLD) and polycystic ovarian syndrome (PCOS). J Transl Med. 2013;11:133. Doi: 10.1186/14795876-11-133

7 Yang R, Yang S, Li R, Liu P, Qiao J, Zhang Y. Effects of hyperandrogenism on metabolic abnormalities in patients with polycystic ovary syndrome: a meta-analysis. Reprod Biol Endocrinol. 2016;14(01):67. Doi: 10.1186/s12958-016-0203-8

8 Kumarendran B, O'Reilly MW, Manolopoulos KN, Toulis KA, Gokhale KM, Sitch AJ, et al. Polycystic ovary syndrome, androgen excess, and the risk of nonalcoholic fatty liver disease in women: A longitudinal study based on a United Kingdom primary care database. PLoS Med. 2018;15(03):e1002542. Doi: 10.1371/journal.pmed.1002542

9 de Medeiros SF, de Medeiros MAS, Barbosa BB, Yamamoto MMW. Relationship of biological markers of body fat distribution and corticosteroidogenic enzyme activities in women with polycystic ovary syndrome. Horm Metab Res. 2019;51(10):639-648. Doi: 10.1055/a-0975-9207

10 Kahal H, Kyrou I, Uthman OA, Brown A, Johnson S, Wall PDH, et al. The prevalence of obstructive sleep apnoea in women with polycystic ovary syndrome: a systematic review and meta-analysis. Sleep Breath. 2020;24(01):339-350. Doi: 10.1007/s11325019-01835-1

11 Sung YA, Oh JY, Chung H, Lee H. Hyperandrogenemia is implicated in both the metabolic and reproductive morbidities of polycystic ovary syndrome. Fertil Steril. 2014;101(03):840-845. Doi: 10.1016/j.fertnstert.2013.11.027

12 Ezeh U, Pall M, Mathur R, Azziz R. Association of fat to lean mass ratio with metabolic dysfunction in women with polycystic ovary syndrome. Hum Reprod. 2014;29(07):1508-1517. Doi: 10.1093/humrep/deu096

13 Couto Alves A, Valcarcel B, Mäkinen VP, Morin-Papunen L, Sebert $S$, Kangas AJ, et al. Metabolic profiling of polycystic ovary syn- drome reveals interactions with abdominal obesity. Int J Obes. 2017;41(09):1331-1340. Doi: 10.1038/ijo.2017.126

14 Zhang B, Wang J, Shen S, Liu J, Sun J, Gu T, et al. Association of androgen excess with glucose intolerance in women with Polycystic Ovary Syndrome. BioMed Res Int. 2018;2018:6869705. Doi: $10.1155 / 2018 / 6869705$

15 Tomlinson JW, Walker EA, Bujalska IJ, Draper N, Lavery GG, Cooper MS, et al. 11beta-hydroxysteroid dehydrogenase type 1: a tissue-specific regulator of glucocorticoid response. Endocr Rev. 2004;25(05):831-866. Doi: 10.1210/er.2003-0031

16 Veilleux A, Rhéaume C, Daris M, Luu-The V, Tchernof A. Omental adipose tissue type 111 beta-hydroxysteroid dehydrogenase oxoreductase activity, body fat distribution, and metabolic alterations in women. J Clin Endocrinol Metab. 2009;94(09):3550-3557. Doi: 10.1210/jc.2008-2011

17 Georgopoulos NA, Papadakis E, Armeni AK, Katsikis I, Roupas ND, Panidis D. Elevated serum androstenedione is associated with a more severe phenotype in women with polycystic ovary syndrome (PCOS). Hormones (Athens). 2014;13(02):213-221. Doi: 10.1007/BF03401335

18 O'Reilly MW, House PJ, Tomlinson JW. Understanding androgen action in adipose tissue. J Steroid Biochem Mol Biol. 2014; 143:277-284. Doi: 10.1016/j.jsbmb.2014.04.008

19 Schiffer L, Kempegowda P, Arlt W, O'Reilly MW. MECHANISMS IN ENDOCRINOLOGY: The sexually dimorphic role of androgens in human metabolic disease. Eur J Endocrinol. 2017;177(03): R125-R143. Doi: 10.1530/EJE-17-0124

20 Hansen PA, Han DH, Nolte LA, Chen M, Holloszy JO. DHEA protects against visceral obesity and muscle insulin resistance in rats fed a high-fat diet. Am J Physiol. 1997;273(05):R1704-R1708. Doi: 10.1152/ajpregu.1997.273.5.R1704

21 Perrini S, Natalicchio A, Laviola L, Belsanti G, Montrone C, Cignarelli A, et al. Dehydroepiandrosterone stimulates glucose uptake in human and murine adipocytes by inducing GLUT1 and GLUT4 translocation to the plasma membrane. Diabetes. 2004;53(01): 41-52. Doi: 10.2337/diabetes.53.1.41

22 Rice SP, Zhang L, Grennan-Jones F, Agarwal N, Lewis MD, Rees DA, et al. Dehydroepiandrosterone (DHEA) treatment in vitro inhibits adipogenesis in human omental but not subcutaneous adipose tissue. Mol Cell Endocrinol. 2010;320(1-2):51-57. Doi: 10.1016/j. mce.2010.02.017

23 Hernandez-Morante JJ, Milagro F, Gabaldon JA, Martinez JA, Zamora S, Garaulet M. Effect of DHEA-sulfate on adiponectin gene expression in adipose tissue from different fat depots in morbidly obese humans. Eur J Endocrinol. 2006;155(04): 593-600. Doi: 10.1530/eje.1.02256

24 McNelis JC, Manolopoulos KN, Gathercole LL, Bujalska IJ, Stewart PM, Tomlinson JW, et al. Dehydroepiandrosterone exerts antiglucocorticoid action on human preadipocyte proliferation, differentiation, and glucose uptake. Am J Physiol Endocrinol Metab. 2013;305(09):E1134-E1144. Doi: 10.1152/ajpendo.00314.2012

25 Lerchbaum E, Schwetz V, Giuliani A, Pieber TR, Obermayer-Pietsch B. Opposing effects of dehydroepiandrosterone sulfate and free testosterone on metabolic phenotype in women with polycystic ovary syndrome. Fertil Steril. 2012;98(05):1318-25.e1. Doi: 10.1016/j.fertnstert.2012.07.1057

26 Goodarzi MO, Carmina E, Azziz R. DHEA, DHEAS and PCOS. J Steroid Biochem Mol Biol. 2015;145:213-225. Doi: 10.1016/j. jsbmb.2014.06.003

27 de Medeiros SF, Barbosa BB, de Medeiros AKLWY, de Medeiros MAS, Yamamoto MMW. Differential effects of various androgens on polycystic ovary syndrome. Horm Metab Res. 2021;53(05): 341-349. Doi: 10.1055/a-1422-3243

28 de Medeiros SF, Ormond CM, de Medeiros MAS, de Souza Santos $\mathrm{N}$, Banhara CR, Yamamoto MMW. Metabolic and endocrine connections of 17-hydroxypregnenolone in polycystic ovary syndrome women. Endocr Connect. 2017;6(07):479-488. Doi: 10.1530/EC-17-0151 
29 Teede HJ, Misso ML, Costello MF, Dokras A, Laven J, Moran L, et al; International PCOS Network. Recommendations from the international evidence-based guideline for the assessment and management of polycystic ovary syndrome. Fertil Steril. 2018;110 (03):364-379. Doi: 10.1016/j.fertnstert.2018.05.004

30 Fraser IS, Critchley HO, Broder M, Munro MG. The FIGO recommendations on terminologies and definitions for normal and abnormal uterine bleeding. Semin Reprod Med. 2011;29(05): 383-390. Doi: 10.1055/s-0031-1287662

31 Wild RA, Vesely S, Beebe L, Whitsett T, Owen W. Ferriman Gallwey self-scoring I: performance assessment in women with polycystic ovary syndrome. J Clin Endocrinol Metab. 2005;90(07):4112-4114. Doi: 10.1210/jc.2004-2243

32 Kristensen SL, Ramlau-Hansen CH, Ernst E, Olsen SF, Bonde JP, Vested A, et al. A very large proportion of young Danish women have polycystic ovaries: is a revision of the Rotterdam criteria needed? Hum Reprod. 2010;25(12):3117-3122. Doi: 10.1093/humrep/deq273

33 de Medeiros SF, Yamamoto MMW, Souto de Medeiros MA, Barbosa BB, Soares JM, Baracat EC. Changes in clinical and biochemical characteristics of polycystic ovary syndrome with advancing age. Endocr Connect. 2020;9(02):74-89. Doi: 10.1530/ EC-19-0496

34 American Diabetes Association. Standards of medical care in diabetes-2010. Diabetes Care. 2010;33(Suppl 1):S11-S61. Doi: $10.2337 / \mathrm{dc} 10-\mathrm{S} 011$

35 James WP. Research on obesity: a report of the DHSS/MRC group HM. London: Stationery Office; 1976

36 Krakauer NY, Krakauer JC. A new body shape index predicts mortality hazard independently of body mass index. PLoS One. 2012;7(07):e39504. Doi: 10.1371/journal.pone.0039504

37 Yang RF, Liu XY, Lin Z, Zhang G. Correlation study on waist circumference-triglyceride (WT) index and coronary artery scores in patients with coronary heart disease. Eur Rev Med Pharmacol Sci. 2015;19(01):113-118

38 Valdez R. A simple model-based index of abdominal adiposity. J Clin Epidemiol. 1991;44(09):955-956. Doi: 10.1016/0895-4356 (91)90059-i

39 Amato MC, Giordano C, Galia M, Criscimanna A, Vitabile S, Midiri M, et al; AlkaMeSy Study Group. Visceral Adiposity Index: a reliable indicator of visceral fat function associated with cardiometabolic risk. Diabetes Care. 2010;33(04):920-922. Doi: 10.2337/dc09-1825

40 Kahn HS, Valdez R. Metabolic risks identified by the combination of enlarged waist and elevated triacylglycerol concentration. Am J Clin Nutr. 2003;78(05):928-934. Doi: 10.1093/ajcn/78.5.928

41 Medeiros SF, Gil-Junior AB, Barbosa JS, Isaías ED, Yamamoto MM. New insights into steroidogenesis in normo- and hyperandrogenic polycystic ovary syndrome patients. Arq Bras Endocrinol Metabol. 2013; 57(06):437-444. Doi: 10.1590/s0004-27302013000600005

42 Nathan DM, Kuenen J, Borg R, Zheng H, Schoenfeld D, Heine RJA1cDerived Average Glucose Study Group. Translating the A1C assay into estimated average glucose values. Diabetes Care. 2008;31 (08):1473-1478. Doi: $10.2337 / \mathrm{dc08}-0545$

43 Matthews DR, Hosker JP, Rudenski AS, Naylor BA, Treacher DF, Turner RC. Homeostasis model assessment: insulin resistance and beta-cell function from fasting plasma glucose and insulin concentrations in man. Diabetologia. 1985;28(07):412-419. Doi: 10.1007/BF00280883

44 Friedewald WT, Levy RI, Fredrickson DS. Estimation of the concentration of low-density lipoprotein cholesterol in plasma, without use of the preparative ultracentrifuge. Clin Chem. 1972;18(06):499-502

45 de Medeiros SF, Yamamoto MM, Bueno HB, Belizario D, Barbosa JS. Prevalence of elevated glycated hemoglobin concentrations in the polycystic ovary syndrome: anthropometrical and metabolic relationship in amazonian women. J Clin Med Res. 2014;6(04): 278-286. Doi: 10.14740/jocmr1829w
46 Medeiros SF, Barbosa JS, Yamamoto MM. Comparison of steroidogenic pathways among normoandrogenic and hyperandrogenic polycystic ovary syndrome patients and normal cycling women. J Obstet Gynaecol Res. 2015;41(02):254-263

47 Huang K, Bao JP, Jennings GJ, Wu LD. The disease-modifying effect of dehydroepiandrosterone in different stages of experimentally induced osteoarthritis: a histomorphometric study. BMC Musculoskelet Disord. 2015;16:178. Doi: 10.1186/s12891-015-0595-1

48 Azziz R, Woods KS, Reyna R, Key TJ, Knochenhauer ES, Yildiz BO. The prevalence and features of the polycystic ovary syndrome in an unselected population. J Clin Endocrinol Metab. 2004;89(06): 2745-2749. Doi: 10.1210/jc.2003-032046

49 Gil Junior AB, Rezende AP, do Carmo AV, Duarte EI, de Medeiros $\mathrm{MM}$, de Medeiros SF. [Adrenal androgen participation in the polycystic ovary syndrome]. Rev Bras Ginecol Obstet. 2010;32 (11):541-548. Doi: 10.1590/s0100-72032010001100005

50 Dunaif $A$. Insulin resistance and the polycystic ovary syndrome: mechanism and implications for pathogenesis. Endocr Rev. 1997; 18(06):774-800. Doi: 10.1210/edrv.18.6.0318

51 Tosi F, Negri C, Brun E, Castello R, Faccini G, Bonora E, et al. Insulin enhances ACTH-stimulated androgen and glucocorticoid metabolism in hyperandrogenic women. Eur J Endocrinol. 2011;164 (02):197-203. Doi: 10.1530/EJE-10-0782

52 Tock L, Carneiro G, Pereira AZ, Tufik S, Zanella MT. Adrenocortical production is associated with higher levels of luteinizing hormone in nonobese women with polycystic ovary syndrome. Int J Endocrinol. 2014;2014:620605. Doi: 10.1155/2014/620605

53 Lerchbaum E, Schwetz V, Rabe T, Giuliani A, Obermayer-Pietsch B. Hyperandrogenemia in polycystic ovary syndrome: exploration of the role of free testosterone and androstenedione in metabolic phenotype. PLoS One. 2014;9(10):e108263. Doi: 10.1371/journal. pone. 0108263

54 Alexiou E, Hatziagelaki E, Pergialiotis V, Chrelias C, Kassanos D, Siristatidis C, et al. Hyperandrogenemia in women with polycystic ovary syndrome: prevalence, characteristics and association with body mass index. Horm Mol Biol Clin Investig. 2017;29(03): 105-111. Doi: 10.1515/hmbci-2016-0047

55 Yanes Cardozo LL, Romero DG, Reckelhoff JF. Cardiometabolic features of polycystic ovary syndrome: role of androgens. Physiology (Bethesda). 2017;32(05):357-366. Doi: 10.1152/physiol.00030.2016

56 Chen MJ, Yang WS, Yang JH, Chen CL, Ho HN, Yang YS. Relationship between androgen levels and blood pressure in young women with polycystic ovary syndrome. Hypertension. 2007;49(06): 1442-1447. Doi: 10.1161/HYPERTENSIONAHA.106.083972

57 Oliveira RdoS, Redorat RG, Ziehe GH, Mansur VA, Conceição FL. Arterial hypertension and metabolic profile in patients with polycystic ovary syndrome. Rev Bras Ginecol Obstet. 2013;35 (01):21-26. Doi: 10.1590/s0100-72032013000100005

58 Amiri M, Ramezani Tehrani F, Behboudi-Gandevani S, BidhendiYarandi R, Carmina E. Risk of hypertension in women with polycystic ovary syndrome: a systematic review, meta-analysis and meta-regression. Reprod Biol Endocrinol. 2020;18(01):23. Doi: 10.1186/s12958-020-00576-1

59 Carmina E, Koyama T, Chang L, Stanczyk FZ, Lobo RA. Does ethnicity influence the prevalence of adrenal hyperandrogenism and insulin resistance in polycystic ovary syndrome? Am J Obstet Gynecol. 1992;167(06):1807-1812. Doi: 10.1016/0002-9378(92) 91779-a

60 Li L, Yang D, Chen X, Chen Y, Feng S, Wang L. Clinical and metabolic features of polycystic ovary syndrome. Int J Gynaecol Obstet. 2007;97(02):129-134. Doi: 10.1016/j.ijgo.2007.01.005

61 Fujioka K, Kajita K, Wu Z, Hanamoto T, Ikeda T, Mori I, et al Dehydroepiandrosterone reduces preadipocyte proliferation via androgen receptor. Am J Physiol Endocrinol Metab. 2012;302(06): E694-E704. Doi: 10.1152/ajpendo.00112.2011 
62 Kochan Z, Karbowska J. Dehydroepiandrosterone up-regulates resistin gene expression in white adipose tissue. Mol Cell Endocrinol. 2004;218(1-2):57-64. Doi: 10.1016/j.mce.2003.12.012

63 Buffington CK, Givens JR, Kitabchi AE. Opposing actions of dehydroepiandrosterone and testosterone on insulin sensitivity. In vivo and in vitro studies of hyperandrogenic females. Diabetes. 1991;40(06):693-700. Doi: 10.2337/diab.40.6.693

64 Yamashita R, Saito T, Satoh S, Aoki K, Kaburagi Y, Sekihara H. Effects of dehydroepiandrosterone on gluconeogenic enzymes and glucose uptake in human hepatoma cell line, HepG2. Endocr J. 2005;52(06):727-733. Doi: 10.1507/endocrj.52.727

65 De Pergola G, Zamboni M, Sciaraffia M, Turcato E, Pannacciulli N, Armellini F, et al. Body fat accumulation is possibly responsible for lower dehydroepiandrosterone circulating levels in premenopausal obese women. Int J Obes Relat Metab Disord. 1996;20 (12):1105-1110

66 Mannic T, Viguie J, Rossier MF. In vivo and in vitro evidences of dehydroepiandrosterone protective role on the cardiovascular system. Int J Endocrinol Metab. 2015;13(02):e24660. Doi: 10.5812 /ijem. 24660

67 Tchernof A, Labrie F. Dehydroepiandrosterone, obesity and cardiovascular disease risk: a review of human studies. Eur J Endocrinol. 2004;151(01):1-14. Doi: 10.1530/eje.0.1510001

68 Moran C, Arriaga M, Arechavaleta-Velasco F, Moran S. Adrenal androgen excess and body mass index in polycystic ovary syndrome. J Clin Endocrinol Metab. 2015;100(03):942-950. Doi: 10.1210/jc.2014-2569

69 Zerradi M, Dereumetz J, Boulet MM, Tchernof A. Androgens, body fat Distribution and Adipogenesis. Curr Obes Rep. 2014;3(04): 396-403. Doi: 10.1007/s13679-014-0119-6

70 Brahimaj A, Ligthart S, Ikram MA, Hofman A, Franco OH, Sijbrands EJG, et al. Serum levels of apolipoproteins and incident type 2 diabetes: a prospective cohort study. Diabetes Care. 2017;40(03): 346-351. Doi: 10.2337/dc16-1295

71 Nestler JE, Clore JN, Blackard WG. Dehydroepiandrosterone: the "missing link" between hyperinsulinemia and atherosclerosis? FASEB J. 1992;6(12):3073-3075. Doi: 10.1096/fasebj.6.12.1387859

72 Farah-Eways L, Reyna R, Knochenhauer ES, Bartolucci AA, Azziz R. Glucose action and adrenocortical biosynthesis in women with polycystic ovary syndrome. Fertil Steril. 2004;81(01):120-125. Doi: 10.1016/j.fertnstert.2003.05.008

73 Morán C, Knochenhauer E, Boots LR, Azziz R. Adrenal androgen excess in hyperandrogenism: relation to age and body mass. Fertil Steril. 1999;71(04):671-674. Doi: 10.1016/s0015-0282(98)00536-6

74 Alpañés M, Luque-Ramírez M, Martínez-García MA, FernándezDurán E, Álvarez-Blasco F, Escobar-Morreale HF. Influence of adrenal hyperandrogenism on the clinical and metabolic phenotype of women with polycystic ovary syndrome. Fertil Steril. 2015;103(03):795-801.e2. Doi: 10.1016/j.fertnstert.2014.12.105

75 Vryonidou A, Papatheodorou A, Tavridou A, Terzi T, Loi V, Vatalas $\mathrm{I}-\mathrm{A}$, et al. Association of hyperandrogenemic and metabolic phenotype with carotid intima-media thickness in young women with polycystic ovary syndrome. J Clin Endocrinol Metab. 2005;90 (05):2740-2746. Doi: 10.1210/jc.2004-2363

76 Carmina E, Lobo RA. Prevalence and metabolic characteristics of adrenal androgen excess in hyperandrogenic women with different phenotypes. J Endocrinol Invest. 2007;30(02):111-116. Doi: $10.1007 /$ BF03347408

77 Brennan K, Huang A, Azziz R. Dehydroepiandrosterone sulfate and insulin resistance in patients with polycystic ovary syndrome. Fertil Steril. 2009;91(05):1848-1852. Doi: 10.1016/j.fertnstert.2008.02.101
78 Chen MJ, Chen CD, Yang JH, Chen C-L, Ho H-N, Yang W-S, et al. High serum dehydroepiandrosterone sulfate is associated with phenotypic acne and a reduced risk of abdominal obesity in women with polycystic ovary syndrome. Hum Reprod. 2011;26(01):227-234. Doi: 10.1093/humrep/deq308

79 Misichronis G, Georgopoulos NA, Marioli DJ, Armeni AK, Katsikis I, Piouka AD, et al. The influence of obesity on androstenedione to testosterone ratio in women with polycystic ovary syndrome (PCOS) and hyperandrogenemia. Gynecol Endocrinol. 2012;28 (04):249-252. Doi: 10.3109/09513590.2011.613965

80 Huang R, Zheng J, Li S, Tao T, Ma J, Liu W. Characteristics and contributions of hyperandrogenism to insulin resistance and other metabolic profiles in polycystic ovary syndrome. Acta Obstet Gynecol Scand. 2015;94(05):494-500. Doi: 10.1111/ aogs. 12612

81 Savastano S, Belfiore A, Guida B, Angrisani L, Orio F Jr, Cascella T, et al. Role of dehydroepiandrosterone sulfate levels on body composition after laparoscopic adjustable gastric banding in pre-menopausal morbidly obese women. J Endocrinol Invest. 2005;28(06):509-515. Doi: 10.1007/BF03347238

82 Simoncini T, Mannella P, Fornari L, Varone G, Caruso A, Genazzani AR. Dehydroepiandrosterone modulates endothelial nitric oxide synthesis via direct genomic and nongenomic mechanisms. Endocrinology. 2003;144(08):3449-3455. Doi: 10.1210/en.20030044

83 Meirow D, Raz I, Yossepowitch O, Brzezinski A, Rosler A, Schenker JG, et al. Dyslipidaemia in polycystic ovarian syndrome: different groups, different aetiologies? Hum Reprod. 1996;11(09):1848-1853. Doi: 10.1093/oxfordjournals.humrep.a019505

84 Köşüş N, Köşüş A, Kamalak Z, Hızlı D, Turhan NÖ Impact of adrenal versus ovarian androgen ratio on signs and symptoms of polycystic ovarian syndrome. Gynecol Endocrinol. 2012;28(08):611-614. Doi: $10.3109 / 09513590.2011 .650770$

85 Schriock ED, Buffington CK, Hubert GD, Kurtz BR, Kitabchi AE, Buster JE, et al. Divergent correlations of circulating dehydroepiandrosterone sulfate and testosterone with insulin levels and insulin receptor binding. J Clin Endocrinol Metab. 1988;66(06): 1329-1331. Doi: 10.1210/jcem-66-6-1329

86 Lea-Currie YR, Wen P, McIntosh MK. Dehydroepiandrosteronesulfate (DHEAS) reduces adipocyte hyperplasia associated with feeding rats a high-fat diet. Int J Obes Relat Metab Disord. 1997;21 (11):1058-1064. Doi: 10.1038/sj.ijo.0800516

87 Gambineri A, Patton L, Vaccina A, Cacciari M, Morselli-Labate AM, Cavazza C, et al. Treatment with flutamide, metformin, and their combination added to a hypocaloric diet in overweight-obese women with polycystic ovary syndrome: a randomized, 12month, placebo-controlled study. J Clin Endocrinol Metab. 2006;91(10):3970-3980. Doi: 10.1210/jc.2005-2250

88 Ingelsson E, Schaefer EJ, Contois JH, McNamara JR, Sullivan L, Keyes MJ, et al. Clinical utility of different lipid measures for prediction of coronary heart disease in men and women. JAMA. 2007;298(07):776-785. Doi: 10.1001/jama.298.7.776

89 Legro RS, Schlaff WD, Diamond MP, Coutifaris C, Casson PR, Brzyski R, et al; Reproductive Medicine Network. Total testosterone assays in women with polycystic ovary syndrome: precision and correlation with hirsutism. J Clin Endocrinol Metab. 2010;95 (12):5305-5313. Doi: $10.1210 / j c .2010-1123$

90 Janse F, Eijkemans MJ, Goverde AJ, Lentjes EGWM, Hoek A, Lambalk CB, Hickey TE, et al. Assessment of androgen concentration in women: liquid chromatography-tandem mass spectrometry and extraction RIA show comparable results. Eur J Endocrinol. 2011;165(06):925-933. Doi: 10.1530/EJE-11-0482 